Job demands-resources: a gender perspective on employee well-being and resilience in retail stores in China

Qihai Huang

Lancaster University Management School

Lancaster, UK

Email: qihai.huang@lancaster.ac.uk

Yijun Xing (corresponding author)

School of Economics and Management

Beijing Jiao Tong University, Beijing, China

Email: dr.yijunxing@gmail.com

Jos Gamble

School of Management

Royal Holloway

University of London

Egham, UK

Email: j.gamble@rhul.ac.uk 


\title{
Job demands-resources: a gender perspective on employee well-being and resilience in retail stores in China
}

\begin{abstract}
Organisational resilience can be promoted through human resource management practices that enhance individual employees' well-being and ability to cope with adversity. However, the extant literature tends to neglect the influence of gender on employee well-being and resilience. Shopfloor employees in retail stores often undertake demanding roles, characterised by considerable pressure and low pay, and attendant high levels of employee turnover. Drawing on the job demands-resources model, by analysing data collected from 697 employees at foreign-invested retail stores in China, this paper found that workload and employee participation in decision-making had a similar impact on the well-being of both male and female employees. However, the impact of job security and emotional demands on employees differed by gender. This paper extends the job demands-resources model by articulating the influence of gender on employee well-being. Additionally, its empirical insights, drawn from an emerging economy context, enable a contribution to the literature on employee well-being and resilience. Relevant implications for human resource management and resilience are discussed.
\end{abstract}

Keywords: resilience, well-being, job demands-resources model, gender, retail, China, HRM 


\section{Introduction}

In rapidly changing marketplace environments, firms which are resilient can maintain a competitive position under challenging conditions (Hamel \& Valikangas, 2003).

Resilience is a desirable characteristic to possess not only for an organisation, but also for its members in order to deal with various types of adversity (Cartwright \& Cooper, 2009; Cooper, 2013; Lengnick-Hall, Beck, \& Lengnick-Hall, 2011; Shin, Taylor, \& Seo, 2012; Tugade \& Fredrickson, 2004). The term 'resilience' commonly refers to both organisational and employee strength, perseverance and the capacity to recover when encountering adversity (Linnenluecke, 2015). Research in organisational behaviour and psychology indicates that employees' experience of workplace stress leads to changes in their physiological, psychological and behavioural functions, which in turn can be detrimental both to their individual health, and to organisational and national productivity (Lundberg \& Cooper, 2011).

Resilience is probably the most important positive resource to help navigate a turbulent society and a stressful workplace (Avey, Luthans, \& Jensen, 2009). Greater employee well-being is associated with better job performance, lower absenteeism, and reduced job turnover, and is therefore of particular interest to firms and other organizations (Frey \& Stutzer, 2002). An organisation's capacity to develop resilience aggregated at the organizational level can be augmented through human resource management (HRM) practices which enhance individual employees' well-being and ability to cope with adversity (Lengnick-Hall et al., 2011). However, studies on individual resilience in an organisational context remain limited (Youssef \& Luthans, 2007). A dominant research focus on achieving business-oriented performance outcomes has obscured the importance of employee well-being at work (Baptiste, 
2008; Guest, 2002). Accordingly, scholars have called for more research on the link between HRM and employee well-being, coping strategies and resilience (Baptiste, 2008; Cooper, 2013; Lengnick-Hall et al., 2011; Linnenluecke, 2015).

In the Chinese context, despite remarkable growth in income per capita, various measures of satisfaction with life or happiness appear not to have risen in recent years (Knight \& Gunatilaka, 2011). Increasingly, researchers have begun to investigate the well-being of Chinese employees (Huang \& Gamble, 2015; Sang, Teo, Cooper, \& Bohle, 2013). While available research has often touched upon gender, few studies have focussed specifically on women's work and careers (Cooke \& Xiao, 2014), or gender and well-being (Huang \& Gamble, 2015). While existing research indicates different coping strategies between male and female workers when faced with stress and burnout (Purvanova \& Muros, 2010), there is limited research on job-related factors affecting the well-being of employees working in the retail sector.

This paper seeks to address the aforementioned gaps. Drawing on the job demandsresources model (Bakker, Demerouti, \& Verbeke, 2004), this study aims to enhance our understanding of the factors that determine male and female frontline workers' well-being in China's retail sector, which in turn has HRM implications. It contributes to the extant literature in the following ways. Firstly, it contributes to nascent literature that links stress and well-being to resilience by enriching the job demandsresources model with a gender perspective. The literature indicates male-female differences in well-being, for example, in stress (Schmaus, Laubmeier, Boquiren, Herzer, \& Zakowski, 2008), and burnout, and accordingly in different coping mechanisms (Purvanova \& Muros, 2010), and different determinants of job 
satisfaction (Huang \& Gamble, 2015). Lack of clarity on the nature of gender differences in the face of such phenomena may generate ungrounded speculation that (mis)informs organisational decisions (Purvanova \& Muros, 2010) and HRM policy. Organisations need to recognize the importance of employee workplace experiences and how gender differences might affect employee well-being, which in turn may lead to varying organisational outcomes in different contexts.

Secondly, this study is among the first to focus on employees' well-being and resilience in China's retail sector. Empirical insights from this emerging economy will allow us to interrogate theory drawn from Western contexts. This paper thus also contributes to the understanding of front-line service sector work, which provides a significant number of jobs but is still under researched (Huang \& Gamble, 2015; Kerfoot \& Korczynski, 2005). Retailing alone employs over 10 percent of the total labour force in advanced economies. Female workers predominate in this sector, which is often associated with jobs considered of low social status and involving poor conditions, such as low wages and limited career prospects (Grugulis \& Bozkurt, 2011).

Studying employee well-being in this context is important since China is already the world's second largest consumer market (Economist, 2014). A thriving domestic Chinese marketplace is critical not only for China's economic health but also for the world economy (Huang, Fidrmuc, \& Fidrmuc, 2015). In the early 1990s, post-Mao China began to open its domestic market to overseas retail companies; the market further substantially liberalised in 2004, in accordance with China's commitments to the World Trade Organisation (WTO). The majority of world's leading retail 
companies now have a presence in China; for many of these companies learning how to deal with an unfamiliar workforce has been a major challenge (Gamble, 2011). Foreign consumer brands and retailers attracted to this huge market need to understand the factors that underpin their employees' well-being, which in turn can contribute to their competitiveness and performance (Sousa-Poza \& Sousa-Poza, 2000).

Every occupation has specific risk factors associated with job-related stress (Bakker et al., 2004); many service sector jobs, including retailing, involve emotional demands and employees often need to manage their emotions effectively to stimulate and meet customer demands, which in turn affect employees' well-being and organisational performance outcomes (Bakker \& Demerouti, 2007; Kerfoot \& Korczynski, 2005). Customers in China can be very demanding and employee turnover in its retail sector is high (Gamble \& Huang, 2009). It is thus critical for retailers to understand how employees can have the psychological resilience which is characterized by the ability to bounce back from negative emotional experiences (Tugade \& Fredrickson, 2004).

The next section reviews the related literature and summarizes the theoretical underpinnings to this study. These inform the hypotheses developed and tested subsequently. The paper then outlines the research methods, followed by the empirical results. The final section comprises the discussion, future research directions and conclusion.

\section{Literature review and hypotheses development}

Resilience, employees' well-being and organisational performance 
Much empirical research has examined resilience at the individual-level as well as organisational-level outcomes (Coutu, 2002). Resilient individuals tend to recover quickly and effectively from stressful experiences (Tugade \& Fredrickson, 2004); resilience can, therefore, positively affect job performance (Wright \& Cropanzano, 2004). From an organisational level, a high engagement culture may be conducive to generating a supportive environment for employees to build resilience and develop coping strategies (Bowles \& Cooper, 2012). The focus of the current paper is at the individual level, as resilience is conducive to individual well-being (Cartwright \& Cooper, 2009; Cooper, 2013).

Much existing research has documented the development of resilience from the psychological perspective (Masten, 2001; Reich, Zautra, \& Hall, 2010) and its manifestation in HRM and organisation and management studies at large (LengnickHall et al., 2011). From a psychological perspective, resilience is largely defined as individuals' effective coping and adaptation when faced with loss, hardship, or adversity (Shin et al., 2012; Tugade \& Fredrickson, 2004). For instance, employees in voluntary organisations exhibit resilience due to the psychological contract geared towards volunteering, this in turn can reduce the influence from state funding bodies' interference (Cunningham, 2010). Furthermore, resilience constitutes a key component of psychological capital (Youssef \& Luthans, 2007), which can be viewed as a positive resource for employees to combat stress (Avey et al., 2009).

In extremely stressful and dangerous situations, individuals' resilience (ability to grow from adversity) and self-efficacy (belief in their abilities) can facilitate the development of entrepreneurial intentions (Bullough, Renko, \& Myatt, 2014). 
However, in a recent literature review on research on resilience in business and management, Linnenluecke (2015) found considerable diversity in defining and operationalizing resilience. Furthermore, there appears to be a disconnection between notions of resilience and prevalent theoretical underpinnings. Accordingly, in this study we attempt to juxtapose resilience and the job demands-resources model. In so doing, we hope to provide an innovative theoretical perspective to advance the resilience literature.

\section{Resilience and the job demands-resources model}

The job demands-resources (JD-R) model provides a helpful theoretical framework that organisations can use to understand employees' well-being and improve their health at work, whilst simultaneously enhancing organisational performance. It argues that every occupation is likely to have its own specific risk factors associated with job stress, which can be grouped into two general categories (i.e. job demands and job resources), thus constituting an overarching model that may be applied to various occupational settings, irrespective of the particular demands and resources involved (Bakker \& Demerouti, 2007). Furthermore, Crawford, LePine, \& Rich (2010) argue that the two overarching categories of job demands and job resources, can have an impact on employees' well-being.

Utilizing the JD-R perspective, Topcic, Baum \& Kabst (2016) distinguish challenge demand high-performance work practices (HPWP) and job resource HPWP. By analysing 197 employees and their work environments, they found a positive relationship between challenge demands and individual stress among employees. In contrast to their research, which aimed to examine the 'dark side' of HPWPs, our 
paper seeks to advance the resilience literature by applying the JD-R model to examine the impact of job demands and resources on employees' well-being from a gender perspective. A recent review conceives of well-being as a dynamic construct that both changes over time and fluctuates within a person (Sonnentag, 2015). Jobrelated factors (job stressors, job resources) are recognized as important predictors of employees' well-being.

According to the JD-R model, job demands are potential initiators of a health impairment process while job resources can initiate a motivational process. Job demands denote the psychological stressors involved in accomplishing the workload, including its amount and the responsibilities placed on an individual in the workplace (Karasek Jr, 1979). Job demands are:

'those physical, psychological, social, or organizational aspects of the job that require sustained physical and/or psychological (cognitive and emotional) effort and are therefore associated with certain physiological and/or psychological costs' (Bakker, Demerouti, \& Verbeke, 2004, p. 86).

Job demands may include aspects such as workload, time pressure, difficult physical environments, and emotional demands (Crawford, LePine, \& Rich, 2010). We focus on two aspects of job demands, which are factors particularly associated with people in the retail occupation (Bakker \& Demerouti, 2007), namely, workload and emotional demand. Retail sector jobs are often characterized by hard work and the need for emotion management to serve customer demands (Bakker \& Demerouti, 2007; Kerfoot \& Korczynski, 2005). 
Job resources refer to physical, psychological, social, or organizational aspects of the job that are (1) functional in achieving work goals; (2) reduce job demands and the associated physiological and psychological costs; or (3) stimulate personal growth and development (Bakker \& Demerouti, 2007, p. 312). Similarly, conservation of resources theory points to the critical role of resources in coping with stressful events, where resources are:

'those objects, personal characteristics, conditions, or energies that are valued in their own right or that are valued because they act as conduits to the achievement or protection of valued resources' (Hobfoll, 2001, p. 339).

Job resources include interpersonal relations, job security, and participation in decision-making (Bakker et al., 2004; Crawford et al., 2010; Hobfoll, 2001). We examine the two latter resources, because these appear to be the most pertinent factors influencing employees in the retailing industry (Huang \& Gamble, 2011).

A gender perspective on resilience and employees' well-being A recent review of five decades of empirical research on gender in the Academy of Management Journal laments the 'stalling of gender research' in recent years (Joshi, Neely, Emrich, Griffiths, \& George, 2015, p. 1469), and suggests that one way forward is to increase awareness and acknowledge gender issues in emerging markets. We seek to make just such a contribution in this paper. The extant literature suggests that there are gender differences in well-being and stress (Schmaus et al., 2008). Men and women also tend to have different coping strategies in dealing with burnout 
(Purvanova \& Muros, 2010). In the Chinese context, Huang \& Gamble (2015) found that some key determinants of job satisfaction are gendered. Similarly, gender plays an important role with particular reference to job design, work organisation, career support, and work-life balance initiatives (Cooke \& Xiao, 2014). A recent study based on 857 employees in 120 retail branches of a financial services firm in the USA, found that gender pay inequality for employees reporting to a female manager exists only among employees in the lowest organizational ranks (Abraham, 2016). This finding suggests the role of gender might influence frontline employees more than employees in other organizational ranks. However, research on resilience and wellbeing from a gender perspective remains a largely uncharted territory.

Situated at the intersection of family life and paid work, one stream of literature examining gender difference in well-being is based on the boundary between work and home (e.g. Clark, 2000; Schieman et al., 2009). Border and boundary theories discuss the flexibility and permeability between work and family (Schieman, Milkie, \& Glavin, 2009). Linked to role theory, research from the JD-R perspective examines the specific occupational conditions that contribute to work-family conflict, i.e., job demands that conflict with family life, or to solving problems and enhancing wellbeing, i.e., resources that aid work-family balance (Bianchi \& Milkie, 2010). Different terms have been used including work to family spill-over, work-family interface, work/family balance, and work-family conflict (Allen, Herst, Bruck, \& Sutton, 2000; Bianchi \& Milkie, 2010; Clark, 2000; Matthews, Wayne, \& Ford, 2014; Schieman et al., 2009). Social role theory emphasizes the causal impact of gender roles on people's beliefs about the behaviour deemed appropriate for each sex. As Eagly (1987, p. 13) describes it: 
'These beliefs are more than beliefs about the attributes of women and men: Many of these expectations are normative in the sense that they describe qualities or behavioural tendencies believed to be desirable for each sex'.

The gender perspective attempts to assess the meanings men and women attach to work and family life and how these ideologies contribute to levels and types of conflict (Bianchi \& Milkie, 2010). Following this approach, we will develop hypotheses designed to assess the potential impact of different job demands and resources on male and female employees' well-being, respectively.

Job demands denote the psychological stressors involved in accomplishing workload, including its amount and the responsibilities placed on an individual in the workplace (Choi, 2008; Choi \& Chen, 2006; Karasek Jr, 1979). Chinese customers tend to ask a lot of questions about products and can become confrontational (Gamble \& Huang, 2009). Consequently, employees in retail stores experience heavy job-related demands, such as time pressure and overtime work, due to high expectations from both the stores' management and customers. Spector, Allen, and Poelmans, et al. (2007) suggest that perceived workload is a key measure of job demands, which reflects the amount of work demand encountered. High job demands show a significant bivariate correlation with poor well-being (Crawford et al., 2010). Furthermore, work overload can spill over to off-work time and cause work-family problems (Bianchi \& Milkie, 2010). Choi \& Chen (2006) found that married female Chinese employees perceived higher family demands than their male counterparts, but 
did not perceive any lower work demands. In a similar vein, such perceived workload may be linked to exhaustion and well-being, regardless of gender. Therefore:

Hypothesis 1a: Workload is associated with male employees' well-being Hypothesis $1 \mathrm{~b}$ : Workload is associated with female employees' well-being As mentioned earlier, much research indicates that emotional engagement with customers is a key characteristic of many service sector jobs including retailing. Managing demanding customers is likely to result in a concurrent loss of resources (i.e., time and energy) and might lead to exhaustion, which is likely to have an immediate negative impact on employees' well-being (Matthews et al., 2014). For example, difficult customers can cause distress to frontline service desk staff (Gamble \& Huang, 2009). While emotional demands and their effects on workers are related to stress, burnout, and satisfaction (Glomb, Kammeyer-Mueller, \& Rotundo, 2004), there may be gender differences in responses to such stress.

According to Huang \& Gamble (2015), in China it tends to be accepted as normal that women predominate in much service sector work. Further, they found interaction with customers positively and significantly associated with female, but not male employees' satisfaction levels. Consistent with gender role theory (Eagly, 1987), Chinese women may be more likely to express and vent their emotional feelings than men because it is generally considered appropriate for women to display their emotions while men are expected to shut off and withdraw under stress. Through the gender socialization process, women learn how to handle emotional and interpersonal 
demands because such skills are central to the socially proscribed female gender role (Purvanova \& Muros, 2010). Accordingly, we propose the following hypotheses:

Hypothesis 2a: Emotional demand is associated with male employees' wellbeing

Hypothesis 2b: Emotional demand is not associated with female employees' well-being

Job resources involve 'the working individual's potential control over his tasks and his conduct during the working day' (Karasek 1979, p. 289); they can foster flexibility and aid the fulfilling of responsibilities (Bakker \& Demerouti, 2007, p. 312). Job security and participation in decision-making are two of the most important aspects of job resources (Bakker et al., 2004; Crawford et al., 2010), under the broad conceptual frame of 'job control' (Schieman et al., 2009). Job insecurity, and economic hardship are among the major stressors to individuals' work and family lives (Bianchi \& Milkie, 2010). By contrast, job security can play a key role in affecting employees’ satisfaction and well-being (Erdogan, Bauer, Truxillo, \& Mansfield, 2012).

China's labour market has undergone a series of reforms since the 1980s; these have largely dismantled the 'iron rice bowl' with the termination of lifetime employment status for workers (Warner, 2012). Not surprisingly, Gamble \& Huang (2008) found that Chinese employees perceived job security as a major concern. Furthermore, their study revealed that job security is associated significantly with retail sector employees' organizational commitment. Employees with greater job security tend to be more satisfied since this helps reduce uncertainty in a rapidly changing 
environment (Erdogan et al., 2012). However, men and women may consider job security differently.

Gendered social role expectations manifest routinely in Chinese culture where men are still expected to be the chief breadwinners, working outside the household to deliver income to the family. Women, by contrast, are assumed to take primary responsibility for household work such as child rearing and day-to-day life chores (Choi \& Chen, 2006; Leung, 2003). A recent study based on interviews with female managers in China revealed the influence of traditional gender roles and collectivist values on their careers (Woodhams, Xian, \& Lupton, 2015). This study reports how female managers could face criticism, 'for rejecting their prescribed social role, for subverting the gender order... or for neglecting their family (p. 4). A Confucian principle captures a central feature of this sexual division of labour: 'Men are primarily outside the home, women are primarily inside the home' (Leung, 2003, p. 360). According to Chinese traditional culture, women were considered more important for managing the family while men engaged in developing their social careers. Women should support their husbands by taking charge of housework and fostering their children, which was regarded as the highest virtue for Chinese women. Moreover, women who sought a social career were deemed as doing something beyond their appropriate role. Such traditional values have an important bearing on HRM practices in contemporary workplaces. As a consequence of these norms, Chinese male and female employees may respond differently to job security. Therefore, we propose the following:

Hypothesis 3a: Job security is associated with male employees' well-being 
Hypothesis $3 b$ : Job security is not associated with female employees' wellbeing

Employee participation is an essential component of high commitment or highperformance work practices (Baptiste, 2008; Topcic, Baum, \& Kabst, 2016). Research in the UK suggests that employee involvement and participation are positively associated with higher levels of job satisfaction and organizational commitment (Cox, Zagelmeyer, \& Marchington, 2006). Employees prefer participative management styles to autocratic styles as the former ensure that workers are informed about organisational issues and convey a symbolic and substantive message that they are trusted (Marchington \& Wilkinson, 2005). Employee stress-related outcomes will depend upon the degree of control or discretion employees possess over their work (Jensen, Patel, \& Messersmith, 2013). Participation in decision-making increases employees' feeling of control over work and is an important job resource (Crawford et al., 2010).

Although state-owned and foreign-invested firms in China appear to implement differing degrees of employee participation, their practice is associated significantly with employee satisfaction in both ownerships (Huang \& Gamble, 2011). Participation in decision-making increases employees' potential control over work processes and their feeling of encouragement and self-determination (Jensen et al., 2013). However, male and female employees' concerns are likely to differ and they might respond differently to such practices. For example, female employees may particularly value flexible work arrangements (Gamble \& Huang, 2009) that help reduce family-work conflict. Consequently, participation could, in turn, improve their 
well-being. Furthermore, employee participation in decision-making may be conducive to creating a supportive environment in organisations. Such an environment can offer job resources for employees to mitigate the stress associated with turbulence in society and organisational change. A recent study on Chinese mergers and acquisitions revealed that employee participation can help employees to deal with emotional instability and increase their well-being in the context of organisational change (Xing \& Liu, 2015). Therefore, the following hypotheses are developed:

Hypothesis 4a: Employee participation in decision-making is associated with male employees' well-being Hypothesis 4b: Employee participation in decision-making is associated with female employees' well-being

\section{Research method}

Data were collected from nine stores owned by UK and Japanese multinational retail firms in six large Chinese cities (Beijing, Shanghai, Tianjin, Guangzhou, Chengdu, and Shenzhen) in 2006. The questionnaire was based upon the well-tested United Kingdom Department of Employment's Workplace Employment Relations Survey. Specific questions were translated from English into Chinese based on discussions with Chinese colleagues to ensure their comprehensibility and applicability with some adaption for the Chinese context. This version was then 'back translated' into English (Brislin, 1970). After comparison with the original any discrepancies were resolved by mutual agreement between the authors involved in the data collection (Mullen, 1995). 
A total of 1,000 questionnaires were distributed, representing approximately 50 per cent of the full-time employees working in the participating stores. Completed questionnaires were returned either directly to the researchers or via a mailbox where respondents worked. Response rates were high at 82 per cent since the firms' personnel departments sanctioned the survey. According to one of the most widely cited research methods books (Gall, Borg, \& Gall, 1996), if the return rate is above 80 per cent, there should be little concern for non-response bias. To reduce the possibility of social desirability bias (Arnold \& Feldman, 1981), the questionnaire stated clearly that it was solely for research purposes and that responses were anonymous. After excluding cases with missing values of the key variables, the sample for analysis in this paper consisted of 697 employees.

In total, about 53 per cent of the sample was female and 62 per cent were aged below 28, with about 40 per cent being married. Most (92\%) had education equivalent to college level or lower, and 18 per cent were in managerial positions, ranging from supervisors to store managers. Table 1 shows the demographic profile of the respondents.

\section{Insert Table 1 about here}

\section{Measures}

Well-being: employees' experience of stress in the workplace can be detrimental to individual well-being (Lundberg \& Cooper, 2011). To be resilient, one strategy that employees can use is psychological detachment, to recover from the mental and 
physical efforts of work (Demerouti, Bakker, Sonnentag, \& Fullagar, 2012). Similarly, psychological detachment from work during off-the-job time is found to facilitate recovery, which is clearly an important aspect of employees' well-being (Sonnentag, Kuttler, \& Fritz, 2010). By contrast, when work stress interferes after office time, it can impair employees' well-being. Because Chinese culture tends to value family over society, Chinese managers tend to consider that work responsibilities interfere with family responsibilities, whereas American managers are more likely to complain that family interferes with work responsibilities (Aryee, Fields, \& Luk, 1999; Spector et al., 2007). Prior research suggests that Western cultures prefer a strict separation between work and non-work activities, whereas Eastern cultures tend to blur the boundary between work and non-work activities (Liu \& Almor, 2016; Uhlmann, Heaphy, Ashford, Zhu, \& Sanchez-Burks, 2013). Therefore, in this study well-being was measured as proxy by following the conceptualisation in terms of recovery and psychological detachment from work (Sonnentag, 2015) by asking the extent to which respondents reported 'I always worry about my job even after the office time' with 5point Likert scales ( $1=$ strongly disagree; $5=$ strongly agree $)$.

Independent variables: similar to Huang \& Gamble (2015) and following Spector et al. (2007) and Choi \& Chen's (2006) measure of job demands, we measured the workload variable by asking respondents to rate the extent 'I always have a lot of work to do'. Job security was measured by respondents' rating of the extent, 'I feel secure for my job in this company'. Employee participation used a five-item scale measuring the extent to which managers consulted employees in five separate aspects. Two sample items were 'Managers consult employees about future plans' and 'Managers consult employees about job arrangement'. This is in line with Huang \& 
Gamble (2011). All variables were assessed with 5-point Likert scales ( 1 = strongly disagree; $5=$ strongly agree). The alpha coefficient of the employee participation scale was 0.82 , higher than the suggested reliability level of 0.70 (Nunnally, 1978). Similar to Schieman et al. (2009), the variable of emotional demand was assessed by job positions which involved direct engagement with customers, and thus require employees to manage their emotions to stimulate and meet customer demand (Ashkanasy \& Daus, 2002; Bakker \& Demerouti, 2007). These include customer service positions, e.g. sales assistant, customer service and checkout. These positions are coded 1, while roles that did not involve 'emotional labour', including positions in the warehouse and clerical staff, were coded 0.

Control variables: we include demographic variables as control variables. Age was measured by cohort, e.g., between 18-21 and 22-27 years old. Marital status was coded as single (0) or married (1). Education was measured by the education level respondents had reached, from junior and high school (coded 1) to postgraduate (coded 5). Since Huang \& Gamble (2011) suggest that it is a significant predictor of employees' job satisfaction levels in China, we also included job rank as a control variable with managerial posts coded 1 and other posts coded 0 .

Data collected from a single survey can raise concern of common method bias (Podsakoff, MacKenzie, Lee, \& Podsakoff, 2003). Following Podsakoff et al. (2003), we conducted Harman's single-factor test on the variables included in the models by using exploratory factor analysis. The results show that the largest factor explained only 21.779 per cent of the variance. We thus concluded that there was no dominant 
factor explaining variance, i.e., there was no problem of common method bias in the data.

\section{Results}

Table 2 summarizes the descriptive statistics and correlations for all the variables used in the analysis. Hierarchical multiple regression analysis was used to test the hypotheses. Following an approach adopted by other researchers (Aletraris, 2010; Bender, Donohue, \& Heywood, 2005; Huang \& Gamble, 2015), the sample was divided and tested for men and women separately.

\section{Insert Table 2 about here}

In the first step, we entered the above mentioned control variables, and then all the other variables in the regression. To check that no risk of multicollinearity was present, we conducted variance inflation factors (VIF) tests. The VIF for the variables in the model were between 1.041 and 1.608 , which confirmed there was no problem of multicollinearity (Hair, Anderson, Tatham, \& William, 1998).

Table 3 shows the results of the regression analysis. All four models were significant. Models $1(\mathrm{p}<0.1)$ and $3(\mathrm{p}<.05)$ only consider the control variables. Both Model 2 (male) and Model 4 (female) were highly significant $(\mathrm{p}=0.000)$. Model 2 (male) was highly significant, with an R square of .191 and an adjusted R square of .171. Model 4 (female) had an R square of .183 and an adjusted R square of .164. In other words, Models 1 and 3 only explain 2.5 and 3.5 per cent of variance respectively. Although these factors did not form part of the hypotheses, it is worth noting that marital status 
was significantly associated with female employees' well-being, while job position was significantly associated with male employees' well-being. The other two control variables, age and education, were not significant. In Models 2 and 4, the independent variables explain about 19.1 and 18.3 per cent of the variance respectively. Workload, emotional demand, job security and participation are all significant predictors of male employees' well-being in Model 2. Therefore, H1a, H2a, H3a and H4a are supported. Similarly, workload and participation are significant predictors of female employees' well-being in Model 4. As we anticipated, emotional demand and job security are not statistically significantly associated with female employees' well-being. Thus, H1b, $\mathrm{H} 2 \mathrm{~b}, \mathrm{H} 3 \mathrm{~b}$ and $\mathrm{H} 4 \mathrm{~b}$ are all supported.

Insert Table 3 about here

\section{Discussion}

\section{Theoretical contribution and managerial implications}

Drawing on the Job Demand-Resources (JD-R) model, we examined factors that influence male and female frontline workers well-being by investigating the two key dimensions of job demands and job resources. Our analysis suggests that two factors, workload and participation in decision-making, have a similar impact on both male and female employees' well-being. However, the influence of the emotional dimension of job demands and job security on employees' well-being varies according to gender.

It has been argued that the two overarching categories of the JD-R model represent the majority of job attributes and other related working conditions (Crawford et al., 
2010). The applicability and impact of the two general categories on employees' wellbeing is generally assumed, irrespective of the particular demands and resources involved in specific occupational settings. Job demands are, potentially, initiators of a health impairment process and job resources are initiators of a motivational process (Bakker \& Demerouti, 2007). We contribute to the JD-R model by illuminating that not all types of job demands and resources have the same impact on employees' wellbeing, in particular from a gender perspective. While some job demands and resources can affect both male and female employees' well-being equally, they may respond differently to other job demands and resources, which in turn have different outcomes on employees' well-being.

Various factors might contribute to the gendered impact of job demands and resources, for example, emotional demand and job security, in our case, on employees' wellbeing. Firstly, most existing studies focus on middle-class or higher socio-economic status categories such as managers and accountants to study employees' wellbeing/work-family conflict (Allen et al., 2000). Such categories might differ significantly from working class employees such as front-line workers in the retail sector. Secondly, influenced by differing gender social role expectations (Eagly, 1987; Huang \& Gamble, 2015), males and females might both perceive job demands differently, and also develop different coping strategies to stress. Situations perceived by individuals in a negative way may have negative effects on their personal motivation, personal success and ability to influence events (Linnenluecke, 2015). Similarly, job demands when appraised by employees as hindrances, are negatively related to engagement, whereas when appraised by employees as challenges they are positively related to engagement (Crawford et al., 2010). In addition, traditional 
Chinese norms expect men to be the 'breadwinners', whereas there is no such expectation on women (Choi \& Chen, 2006). Hence, job security, which is normally seen as a resource to employees' well-being in the literature, does not appear to affect Chinese female employees' well-being. This result may be attributed largely to the influence of traditional cultural values in contemporary Chinese society and workplaces (Xing et al., 2016). Furthermore, women might be better equipped to handle emotional and interpersonal demands than men because through the gender socialization process, they have developed the skills socially proscribed for their gender role (Purvanova \& Muros, 2010). Accordingly, emotional demands are not associated with female employees' well-being.

Our findings have several implications with regard to HR interventions in dealing with resilience, taking possible gender differences into consideration. Organisations need to understand employees' responses to differing job demands and resources at work. Firstly, we show that certain HR practices can facilitate employees' well-being. For instance, employee participation in decision-making is closely related to employees' well-being, regardless of gender. This means HR managers may design HR systems that embrace and support participative decision-making. HR managers can positively affect employees' well-being by creatively designing appropriate HR practices to encourage employees' participation in decision-making. Secondly, job security, as a resource, may be valued more by male employees. As our analysis suggests, job security is not associated with female employees' well-being. Instead, they value flexible work arrangements which enable them to fulfil family responsibilities (Gamble \& Huang, 2009). As the prevailing gender role social 
expectation suggests, men are expected to be the main breadwinners while women play a major role in the domestic sphere.

With regard to employee participation in decision-making, HR managers may consider promoting practices that encourage employees to find better ways to arrange workload arrangement, for example, job redesign. Training or coaching sessions may also help employees cope with job demands such as workload. Further, these sessions can provide a platform for employees to release their emotional stress. A nuanced approach with respect to gender should be encouraged when HR managers design and implement different HRM practices. Our study reveals that gender roles can play out differently according to different situations. Accordingly, HRM practices designed to cope with stress and to develop resilience need to consider 'gender sensitivity'. This requires HR managers to be cautious about the nuances and complexity of gender in connection with employees' well-being. For example, since female employees are more likely to be caught by work-family conflict, family-friendly policies such as flexible working hours, can have positive benefits not only for employees, but also for their organisation (Huang \& Gamble, 2015).

\section{Limitations and future research directions}

Our research has several limitations, which also suggest untapped territory for future investigation. First, our empirical setting comprised Chinese employees in foreigninvested firms in the service sector. Hence, influences from both the industry characteristics and the ownership structure might be present. Therefore, we encourage future research to go beyond this empirical setting to test our conceptualization of resilience and well-being. Second, we only refer to one particular theoretical 
perspective of the JD-R model to offer an illustrative example of how this perspective can contribute to an emerging research agenda, such as resilience and well-being. Future research can use our findings as a stepping stone to examine the broader utility of the JD-R model. In view of the fragmented nature of resilience research (Linnenluecke, 2015), we encourage scholars to examine other dimensions of the JD$\mathrm{R}$ model and to use other theoretical perspectives to advance the study of resilience. Third, our attempt to explicate the nuances of gender influence is limited to the scope of employees' well-being in terms of recovery and psychological detachment from work. As argued, well-being is a dynamic construct that changes over time and fluctuates within a person (Sonnentag, 2015). Future research can examine other aspects and their relevance to employee resilience. Our study also has implications for the emerging research agenda on 'diversity management and HRM'; it suggests a fruitful line of inquiry to bridge the research streams on gender and diversity management. By articulating the influence of gender on resilience and well-being, our results may offer an attempt to tackle the grand challenges facing gender research in today's dynamic and fast changing society (Joshi et al., 2015).

\section{Conclusion}

Drawing upon the JD-R model and using survey data on frontline employees in China's retail sector, this paper found that the impact of four key aspects of job demands and resources on employees' well-being is contingent upon gender. Our paper contributes to the recent conceptualization of dynamics of well-being by focusing on the job-related predictors (job stressors and job resources) (Sonnentag, 2015). It also enhances our understanding of relatively under researched frontline workers in the retail sector, whose gendered responses to the impact of the job 
demands and resources on well-being, in turn can help inform HR policies designed to increase resilience. We hope that our research can encourage future researchers to examine other aspects of the JD-R model and its capacity, when combined with other theoretical perspectives, to better understand employees' well-being and resilience. 


\section{References}

Abraham, M. (2016). Pay formalization revisited: Considering the effects of manager gender and discretion on closing the wage gap. Academy of Management Journal, Published online before print March 24, 2016. doi: 10.5465/amj.2013.1060

Aletraris, L. (2010). How satisfied are they and why? A study of job satisfaction, job rewards, gender and temporary agency workers in Australia. Human Relations, 63(8), 11291155.

Allen, T. D., Herst, D. E., Bruck, C. S., \& Sutton, M. (2000). Consequences associated with work-to-family conflict: a review and agenda for future research. Journal of Occupational Health Psychology, 5(2), 278-308.

Arnold, H. J., \& Feldman, D. C. (1981). Social desirability response bias in self-report choice situations. Academy of Management Journal, 24(2), 377-385.

Aryee, S., Fields, D., \& Luk, V. (1999). A cross-cultural test of a model of the work-family interface. Journal of Management, 25(4), 491-511.

Ashkanasy, N. M., \& Daus, C. S. (2002). Emotion in the workplace: The new challenge for managers. The Academy of Management Executive, 16(1), 76-86.

Avey, J. B., Luthans, F., \& Jensen, S. M. (2009). Psychological capital: A positive resource for combating employee stress and turnover. Human Resource Management, 48(5), 677-693.

Bakker, A. B., \& Demerouti, E. (2007). The job demands-resources model: State of the art. Journal of Managerial Psychology, 22(3), 309-328.

Bakker, A. B., Demerouti, E., \& Verbeke, W. (2004). Using the job demands-resources model to predict burnout and performance. Human Resource Management, 43(1), 83-104.

Baptiste, N. R. (2008). Tightening the link between employee wellbeing at work and performance: A new dimension for HRM. Management Decision, 46(2), 284-309.

Bender, K. A., Donohue, S. M., \& Heywood, J. S. (2005). Job satisfaction and gender segregation. Oxford Economic Papers, 57(3), 479-496.

Bianchi, S. M., \& Milkie, M. A. (2010). Work and family research in the first decade of the 21st century. Journal of Marriage and Family, 72(3), 705-725.

Bowles, D., \& Cooper, C. L. (2012). The high engagement work culture: Balancing me and we. Basingstoke: Palgrave Macmillan.

Brislin, R. W. (1970). Back-translation for cross-cultural research. Journal of Cross-Cultural Psychology, 1(3), 185-216.

Bullough, A., Renko, M., \& Myatt, T. (2014). Danger zone entrepreneurs: The importance of resilience and self-efficacy for entrepreneurial intentions. Entrepreneurship Theory and Practice, 38(3), 473-499.

Cartwright, S., \& Cooper, C. L. (2009). The Oxford handbook of organizational well-being. Oxford: Oxford University Press.

Choi, J. (2008). Work and family demands and life stress among Chinese employees: The mediating effect of work-family conflict. The International Journal of Human Resource Management, 19(5), 878-895.

Choi, J., \& Chen, C. C. (2006). Gender differences in perceived work demands, family demands, and life stress among married Chinese employees. Management and Organization Review, 2(2), 209-229.

Clark, S. C. (2000). Work/family border theory: A new theory of work/family balance. Human Relations, 53(6), 747-770.

Cooke, F. L., \& Xiao, Y. (2014). Gender roles and organizational HR practices: The case of women's careers in accountancy and consultancy firms in China. Human Resource Management, 53(1), 23-44.

Cooper, C. L. (2013). From Stress to Wellbeing Volume 1: The Theory and Research on Occupational Stress and Wellbeing (Vol. 1). Basingstoke: Palgrave Macmillan.

Coutu, D. L. (2002). How resilience works. Harvard Business Review, 80(5), 46-56. 
Cox, A., Zagelmeyer, S., \& Marchington, M. (2006). Embedding employee involvement and participation at work. Human Resource Management Journal, 16(3), 250-267.

Crawford, E. R., LePine, J. A., \& Rich, B. L. (2010). Linking job demands and resources to employee engagement and burnout: a theoretical extension and meta-analytic test. Journal of Applied Psychology, 95(5), 834-848.

Cunningham, I. (2010). Drawing from a bottomless well? Exploring the resilience of valuebased psychological contracts in voluntary organizations. The International Journal of Human Resource Management, 21(5), 699-719.

Demerouti, E., Bakker, A. B., Sonnentag, S., \& Fullagar, C. J. (2012). Work-related flow and energy at work and at home: A study on the role of daily recovery. Journal of Organizational Behavior, 33(2), 276-295.

Eagly, A. H. (1987). Sex differences in social behavior: A social-role interpretation. Hillsdale, NJ: Lawrence Eribaum.

Economist, T. (2014). The world's second biggest consumer. Retrieved 20 April, 2016, from http://www.economist.com/blogs/analects/2014/02/chinas-economy

Erdogan, B., Bauer, T. N., Truxillo, D. M., \& Mansfield, L. R. (2012). Whistle while you work: A review of the life satisfaction literature. Journal of Management, 38(4), 1038-1083.

Frey, B. S., \& Stutzer, A. (2002). Happiness and economics: How the economy and institutions affect well-being. Princeton: Princeton University Press.

Gall, M. D., Borg, W. R., \& Gall, J. P. (1996). Educational research: An introduction (6th edition). White Plains, NY: Longman Publishing.

Gamble, J. (2011). Multinational retailers and consumers in China: Transferring organizational practices from the United Kingdom and Japan. London, Palgrave.

Gamble, J., \& Huang, Q. (2009). One store, two employment systems: Core, periphery and flexibility in China's retail sector. British Journal of Industrial Relations, 47(1), 1-26.

Glomb, T. M., Kammeyer-Mueller, J. D., \& Rotundo, M. (2004). Emotional labor demands and compensating wage differentials. Journal of Applied Psychology, 89(4), 700-714.

Grugulis, I., \& Bozkurt, Ö. (2011). Retail work. Hampshire: Palgrave Macmillan.

Guest, D. (2002). Human resource management, corporate performance and employee wellbeing: Building the worker into HRM. Journal of Industrial Relations, 44(3), 335-358.

Hair, J. F., Anderson, R. E., Tatham, R. L., \& William, C. (1998). Multivariate data analysis. Upper Saddle River, NJ: Prentice Hall.

Hamel, G., \& Valikangas, L. (2003). The quest for resilience. Harvard Business Review, $81(9), 52-65$.

Hobfoll, S. E. (2001). The influence of culture, community, and the nested-self in the stress process: Advancing conservation of resources theory. Applied Psychology, 50(3), 337-421.

Huang, Q., \& Gamble, J. (2011). Informal institutional constraints and their impact on HRM and employee satisfaction: Evidence from China's retail sector. The International Journal of Human Resource Management, 22(15), 3168-3186.

Huang, Q., \& Gamble, J. (2015). Social expectations, gender and job satisfaction: Front-line employees in China's retail sector. Human Resource Management Journal, 25(3), 331-347.

Huang, S., Fidrmuc, J., \& Fidrmuc, J. (2015). Whither China? Reform and economic integration among Chinese regions. China Economic Review, 33, 94-110.

Jensen, J. M., Patel, P. C., \& Messersmith, J. G. (2013). High-performance work systems and job control: Consequences for anxiety, role overload, and turnover intentions. Journal of Management, 39(6), 1699-1724.

Joshi, A., Neely, B., Emrich, C., Griffiths, D., \& George, G. (2015). Gender research in AMJ: An overview of five decades of empirical research and calls to action. Academy of Management Journal, 58(5), 1459-1475.

Karasek Jr, R. A. (1979). Job demands, job decision latitude, and mental strain: Implications for job redesign. Administrative Science Quarterly, 24(2), 285-308. 
Kerfoot, D., \& Korczynski, M. (2005). Gender and service: New directions for the study of 'front-line' service work. Gender, Work \& Organization, 12(5), 387-399.

Knight, J., \& Gunatilaka, R. (2011). Does economic growth raise happiness in China? Oxford Development Studies, 39(01), 1-24.

Lengnick-Hall, C. A., Beck, T. E., \& Lengnick-Hall, M. L. (2011). Developing a capacity for organizational resilience through strategic human resource management. Human Resource Management Review, 21(3), 243-255.

Leung, A. S. (2003). Feminism in transition: Chinese culture, ideology and the development of the women's movement in China. Asia Pacific Journal of Management, 20(3), 359374.

Linnenluecke, M. K. (2015). Resilience in business and management research: A review of influential publications and a research agenda. International Journal of Management Reviews, Article first published online: 20 JUL 2015. doi: 10.1111/ijmr.12076

Liu, Y., \& Almor, T. (2016). How culture influences the way entrepreneurs deal with uncertainty in inter-organizational relationships: The case of returnee versus local entrepreneurs in China. International Business Review, 25(1), 4-14.

Lundberg, U., \& Cooper, C. L. (2011). The science of occupational health: stress, psychobiology, and the new world of work. Oxford: John Wiley \& Sons.

Marchington, M., \& Wilkinson, A. (2005). Direct participation and involvement. In S. Bach (Ed.), Managing human resources: personnel management in transition (pp. 398423). Malden, MA: Blackwell Publishing.

Masten, A. S. (2001). Ordinary magic: Resilience processes in development. American Psychologist, 56(3), 227.

Matthews, R. A., Wayne, J. H., \& Ford, M. T. (2014). A work-family conflict/subjective well-being process model: A test of competing theories of longitudinal effects. Journal of Applied Psychology, 99(6), 1173.

Mullen, M. R. (1995). Diagnosing measurement equivalence in cross-national research. Journal of International Business Studies, 573-596.

Nunnally, J. (1978). Psychometric theory. New York: McGraw-Hill.

Podsakoff, P. M., MacKenzie, S. B., Lee, J.-Y., \& Podsakoff, N. P. (2003). Common method biases in behavioral research: A critical review of the literature and recommended remedies. Journal of Applied Psychology, 88(5), 879.

Purvanova, R. K., \& Muros, J. P. (2010). Gender differences in burnout: A meta-analysis. Journal of Vocational Behavior, 77(2), 168-185.

Reich, J. W., Zautra, A. J., \& Hall, J. S. (2010). Handbook of adult resilience. New York: Guilford Press.

Sang, X., Teo, S. T., Cooper, C. L., \& Bohle, P. (2013). Modelling occupational stress and employee health and wellbeing in a Chinese Higher Education Institution. Higher Education Quarterly, 67(1), 15-39.

Schieman, S., Milkie, M. A., \& Glavin, P. (2009). When work interferes with life: Worknonwork interference and the influence of work-related demands and resources. American Sociological Review, 74(6), 966-988.

Schmaus, B. J., Laubmeier, K. K., Boquiren, V. M., Herzer, M., \& Zakowski, S. G. (2008). Gender and stress: Differential psychophysiological reactivity to stress reexposure in the laboratory. International Journal of Psychophysiology, 69(2), 101-106.

Shin, J., Taylor, M. S., \& Seo, M.-G. (2012). Resources for change: The relationships of organizational inducements and psychological resilience to employees' attitudes and behaviors toward organizational change. Academy of Management Journal, 55(3), 727-748.

Sonnentag, S. (2015). Dynamics of well-being. Annual Review of Organizational Psychology and Organizational Behavior, 2, 261-293.

Sonnentag, S., Kuttler, I., \& Fritz, C. (2010). Job stressors, emotional exhaustion, and need for recovery: A multi-source study on the benefits of psychological detachment. Journal of Vocational Behavior, 76(3), 355-365. 
Sousa-Poza, A., \& Sousa-Poza, A. A. (2000). Well-being at work: A cross-national analysis of the levels and determinants of job satisfaction. The Journal of Socio-economics, 29(6), 517-538.

Spector, P. E., Allen, T. D., Poelmans, S. A., Lapierre, L. M., Cooper, C. L., et al. (2007). Cross-national differences in relationships of work demands, job satisfaction, and turnover intentions with work-family conflict. Personnel Psychology, 60(4), 805-835.

Topcic, M., Baum, M., \& Kabst, R. (2016). Are high-performance work practices related to individually perceived stress? A job demands-resources perspective. The International Journal of Human Resource Management, 27(1), 45-66.

Tugade, M. M., \& Fredrickson, B. L. (2004). Resilient individuals use positive emotions to bounce back from negative emotional experiences. Journal of Personality and Social Psychology, 86(2), 320.

Uhlmann, E. L., Heaphy, E., Ashford, S. J., Zhu, L., \& Sanchez-Burks, J. (2013). Acting professional: An exploration of culturally bounded norms against nonwork role referencing. Journal of Organizational Behavior, 34(6), 866-886.

Warner, M. (2012). Whither Chinese HRM? Paradigms, models and theories. The International Journal of Human Resource Management, 23(19), 3943-3963.

Woodhams, C., Xian, H., \& Lupton, B. (2015). Women managers' careers in China: Theorizing the influence of gender and collectivism. Human Resource Management, 54(6), 913-931.

Wright, T. A., \& Cropanzano, R. (2004). The role of psychological well-being in job performance: A fresh look at an age-old quest. Organizational Dynamics, 33(4), 338351.

Xing, Y., \& Liu, Y. (2015). Linking leaders' identity work and human resource management involvement: the case of sociocultural integration in Chinese mergers and acquisitions. The International Journal of Human Resource Management, Published online: 22 Apr 2015, 1-28.

Xing, Y., Liu, Y., Tarba, S. Y., \& Wood, G. (2016). A cultural inquiry into ambidexterity in supervisor-subordinate relationship. The International Journal of Human Resource Management, Published online: 16 Mar 2016, 1-20. doi: DOI:10.1080/09585192.2015.1137619

Youssef, C. M., \& Luthans, F. (2007). Positive organizational behavior in the workplace: The impact of hope, optimism, and resilience. Journal of Management, 33(5), 774-800. 
Table 1 Demographic profile of respondents

\begin{tabular}{|l|r|r|r|}
\hline Gender & Male & Female & Total \\
\hline Age & 47.6 & 53.4 & 100 \\
18-21 years old & 12.5 & 13.4 & \\
$22-27$ years old & 54.3 & 43.5 & 13.0 \\
$28-33$ years old & 22.3 & 31.5 & 54.1 \\
$34-39$ years old & 6.3 & 7.4 & 27.1 \\
40 years old and over & 4.8 & 4.2 & 6.8 \\
\hline Marital status & & & 4.5 \\
Single & 71.3 & 51.2 & 60.7 \\
Married & 28.7 & 48.8 & 39.3 \\
\hline
\end{tabular}




\begin{tabular}{|l|r|r|r|}
\hline Education & 2.5 & & \\
Junior \& high school & 68.1 & 3.4 & 3.0 \\
Senior high school & 20.6 & 69.9 & 69.0 \\
College & 8.5 & 20.4 & 20.5 \\
University & 0.3 & 6.1 & 7.3 \\
Postgraduate & 79.7 & 0.2 & 0.2 \\
\hline Job rank: Ordinary employees & 21.3 & 83.8 & 82.0 \\
\multicolumn{1}{|c|}{ Managerial } & & 16.2 & 18.0 \\
\hline
\end{tabular}

$\mathrm{n}=697$ 
Table 2 Means, standard deviations and correlations

\begin{tabular}{|l|l|l|l|l|l|l|l|l|l|l|}
\hline & Mean & S. D. & 1 & 2 & 3 & 4 & 5 & 6 & 7 & 8 \\
\hline 1.Marital status & .39 & .488 & & $.578^{* * *}$ & -.033 & $.140^{* * *}$ & $.097 * * *$ & .031 & -.027 & $.076^{* *}$ \\
\hline 2.Age & 2.42 & .9832 & & & .001 & $.218^{* * *}$ & $.127^{* * *}$ & $.101^{* * *}$ & .019 & .054 \\
\hline 3.Education & 2.33 & .663 & & & & $.284^{* * *}$ & -.054 & .049 & -.011 & .005 \\
\hline 4.Job rank & .18 & .384 & & & & & .035 & $.329^{* * *}$ & $.078^{* *}$ & $.145^{* * *}$ \\
\hline 5.Workload & 3.57 & .903 & & & & & & $.103^{* * *}$ & $.143^{* * *}$ & $.344^{* * *}$ \\
\hline 6.Emotional demand & .63 & .484 & & & & & & & .046 & $.150^{* * *}$ \\
\hline 7.Job security & 3.56 & .835 & & & & & & & & $.175^{* * *}$ \\
\hline 8.Participation & 3.56 & .831 & & & & & & & & \\
\hline
\end{tabular}

$\mathrm{n}=697, * \mathrm{p}<0.1 ; * * \mathrm{p}<0.05 ; * * * \mathrm{p}<0.001$ 
Table 3 Hierarchical multiple regression analysis results

Male Female

Standardised beta coefficients (t-statistics) Standardised beta coefficients (t-statistics)

\begin{tabular}{|l|l|l|l|l|}
\hline $\begin{array}{l}\text { Independent } \\
\text { variables }\end{array}$ & Model 1 & Model 2 & Model 3 & Model 4 \\
\hline Marital & $.023(.347)$ & $.049(.826)$ & $.158(2.461)^{* *}$ & $.121(2.020)^{* *}$ \\
\hline Age cohort & $-.016(-.243)$ & $-.062(-1.022)$ & $-.072(-1.107)$ & $-.087(-1.431)$ \\
\hline Education level & $.004(.064)$ & $.070(1.344)$ & $-.054(-.979)$ & $-.060(-1.175)$ \\
\hline Job rank & $.156(2.716)^{* * *}$ & $.118(2.154) * *$ & $.133(2.361)^{* *}$ & $.093(1.683)$ \\
\hline Workload & & $.243(4.699) * * *$ & & $362(7.415) * * *$ \\
\hline $\begin{array}{l}\text { Emotional } \\
\text { demand }\end{array}$ & & $.104(1.995) * *$ & & $.029(.546)$ \\
\hline Job security & & $.204(3.860) * * *$ & & $-.015(.301)$ \\
\hline Participation & & $.145(2.752)^{* * *}$ & & $.133(2.627)^{* * *}$ \\
\hline R & .159 & .438 & .188 & .427 \\
\hline R2 & .025 & .191 & .035 & .183 \\
\hline Adjusted R2 & .013 & .171 & .025 & .164 \\
\hline F & $2.112 *$ & $16.549 * * *$ & $3.313 * *$ & $16.060 * * *$ \\
\hline
\end{tabular}

$\mathrm{n}=697, * \mathrm{p}<0.1 ; * * \mathrm{p}<0.05 ; * * * \mathrm{p}<0.001$ 